\title{
Assessment of Knowledge, Attitude and Practice of Tuberculosis Transmission and Prevention Among Tuberculosis Patients at Kuyyu Hospital, North Shoa Zone, Oromia Regional State, Ethiopia
}

\author{
(1) Masresha Leta Ato, ${ }^{1}$ 을 Maleda Tefera Sis² \\ 'Department of Midwifery, Harar Health Science College, Harar, Ethiopia \\ ${ }^{2}$ Department of Nursing, Haramaya University, Harar, Ethiopia
}

\section{ABSTRACT}

Objectives: Tuberculosis is an infectious disease that arises from the bacillus Mycobacterium tuberculosis, which typically affects the lungs (pulmonary Tuberculosis) but may affect other sites as well (extrapulmonary Tuberculosis). This disease is spread through the air when people who are sick with pulmonary Tuberculosis expel bacteria. Tuberculosis continues to be a major public health problem throughout the world, including Ethiopia. In this study, we aim to assess knowledge, attitude, the practice (KAP) of tuberculosis transmission and prevention among patients with Tuberculosis in Kuyyu Hospital, North Shoa Zone, Oromia Region, Ethiopia, 2018 Gregorian Calender.

Please cite this article as: Ato ML, Sis MT. Assessment of Knowledge, Attitude and Practice of Tuberculosis Transmission and Prevention Among Tuberculosis Patients at Kuyyu Hospital, North Shoa Zone, Oromia Regional State, Ethiopia. Anatol J Family Med 2019;2(3):91-97.

Address for correspondence: Dr. Masresha Leta Ato. Department of Midwifery, Harar Health Science College, Harar, Ethiopia

Phone: +0911947787

E-mail:

masreshaleta3@gmail.com

Received Date: 03.12.2018

Accepted Date: 18.02.2019

Published online: 21.11.2019

(C) Copyright 2019 by Anatolian Journal of Family Medicine -

Available online at Www.anatoljfm.org OPEN ACCESS

Methods: In this study, facility-based cross-sectional quantitative study design was used to assess KAP of Tuberculosis transmission and prevention among Tuberculosis patients in Kuyyu Hospital, North Shoa Zone, Oromia Region, Ethiopia, 2018G.C. The information was collected through an interview using structured questionnaires. The collected data were analyzed by tallying, organizing, and calculating manually using a scientific calculator. Descriptive statistics, such as frequencies and percentages of different variables, were computed as appropriate.

Results: From 108 respondents, 68 (62.9\%) were male and 40 (37.1\%) were female. Concerning the respondent's knowledge about TB, out of 108 respondents, 46 (42.6\%) of them heard about TB from health institutions at health education programs. Regarding the attitude from a total of 108 respondents, $83(76.8 \%)$ of them agreed that TB transmitted can be by coughing, $5(4.6 \%)$ of them disagreed and $20(18.6 \%)$ of them were neutral. Regarding the practice from a total of 108 respondents, $58(53.7 \%)$ of them responded that they opened windows when they were at home and 50 (46.3\%) of them said that they did not open windows when they were at home.

Conclusion: To minimize the number of patients who engage in traditional methods of TB transmission and prevention methods, education and training should be given by the hospital in collaboration with other stakeholders, such as Kebele administration, other government offices and international and local NGOs. The hospital and other concerned governmental organizations, non-governmental and community-based organizations should give special attention to patients in providing necessary and basic information in relation to the transmission, prevention and controlling TB.

Keywords: Attitude, knowledge, tuberculosis

\section{INTRODUCTION}

Tuberculosis (TB) is an infectious disease that arises from the bacterium Mycobacterium TB, which typically affects the lungs (pulmonary TB) but may affect other sites as well (extrapulmonary TB). The disease is spread through the air when people who are sick with pulmonary 
TB expel bacteria. TB is also more common among men than women and affects mostly adults in the economically productive age groups. The probability of developing TB is much higher among people infected with the human immunodeficiency virus HIV. ${ }^{[1]}$

TB primarily attacks the lungs, but may also affect other parts of the body in up to one-third of cases. TB is transmitted through the air from infectious people to other people while coughing, sneezing, singing, or talking. A single cough may bring out up to 4.000 droplets. Most infections do not have symptoms, known as latent TB. It is estimated that up to $10 \%$ of infected persons may gradually develop active TB in their lifetime and fatality may reach up to $50 \%$ of the patients if left untreated. ${ }^{[2]}$

TB is a major global health problem. TB causes ill-health among millions of people each year and ranks alongside the HIV as a leading cause of death worldwide. In 2014, there were an estimated 9.6 million new TB cases: 5.4 million among men, 3.2 million among women and 1.0 million among children. ${ }^{[6]}$ The spread of this disease is fuelled by several factors, notably the HIV/AIDS epidemic, low socioeconomic status, overcrowding and malnutrition. ${ }^{[3]}$

African countries in the south of the Sahara, including Ethiopia, are heavily affected by TB. The World Health Organization (WHO) global reports on TB showed that Ethiopia is among the ten top high burden countries regarding the prevalence or incidence cases of TB. ${ }^{[4]}$ However, the real burden of TB in Ethiopia is not known due to several reasons. First, there is neither a reliable disease notification system nor has any regular nationwide epidemiological.

A survey of TB and HIV are conducted. Second, Ethiopia has poorly developed diagnostic facilities and low health service coverage, which might contribute to the very low case detection rate. ${ }^{[5]} \mathrm{TB}$ is a major public problem throughout the world; about a third of the world's population is estimated to be infected with tubercle bacilli and hence at risk of developing active disease. In 2014, there were an estimated 9.6 million new TB cases: 5.4 million among men, approximately 3.2 million among women and 1.0 million among children were affected; approximately t $26 \%$ of the incident TB cases occurred in Africa in 2010. The proportion of TB cases co-infected with HIV highest in countries in the African region, overall the African region, accounted for $82 \%$ of the TB cases among people living with HIV. ${ }^{[6]}$ In 2016, there were an estimated 10.4 million new cases of TB worldwide, and a total of 1.7 million people died from TB (including 0.4 million people with HIV).TB was one of the top ten causes of death worldwide. ${ }^{[7]}$

The 22 high burden countries (HBCs) that have been given the highest priority at the global level since 2000 accounted for $81 \%$ of all estimated cases worldwide. These countries have been the focus of intensified efforts in Direct Observed Treatments (DOTs) expansion from the total 1 million deaths due to TB among HIV-negative people; approximately $80 \%$ occurred in the $22 \mathrm{HBCs}$.

According to the WHO 2011 report, globally, 3.2\% (290.000) of the incident cases of TB are estimated to have multidrugresistant TB (MDR -TB). There are 27 identified high burden countries that carry $86 \%$ of the world's MDR-TB burden. ${ }^{[5]}$

Ethiopia placed 7 among the world's 22 high burden countries, which had an incidence and prevalence rates of 210 and 200 cases per 100.000 people in the year 2014, respectively. ${ }^{[8]}$

Poor knowledge of symptoms indicative of TB and visiting traditional healers could be a reason for the delay in seeking proper medical advice. Deficiencies in the national TB control program are compounded with widespread misconception and false beliefs among patients with TB. These myths have turned TB into a social stigma. This stigmatization can play an important role in the reluctance of patients in self-referral and seeking treatment. Future education should be based on existing scientific knowledge and presented in a manner that can be easily comprehended and accepted the patient's social and cultural factors. These should be taken in to account as they play an important role in the compliance of patients with TB. ${ }^{[7]}$ In this context, Knowledge, attitude and practice (KAP) study is essential to help plan, implement and evaluate TB activities. KAP may identify the knowledge gap, cultural beliefs and behavioral patterns that may facilitate understanding and action as well as may pose problems or build barriers for TB transmission and prevention effort. The results enable to set TB program priorities and to identify determinants of behavioral changes.

\section{METHOD}

Facility based cross-sectional descriptive study was used to assess the KAP of TB transmission and prevention among TB patients in Kuyyu Hospital from May1 to May 30/2018, among 108 randomly selected Tb patients from Kuyyu Hospital. This study was conducted at Kuyyu Hospital, which is one of the 14 Woreda, found in the north Shoa zone of the Oromia region. Kuyyu Woreda is situated about 2600-2800 meters above sea level, $178 \mathrm{~km}$ far from the capital city of Country Addis Ababa and has a Dega climate. There are one District hospital and six health centers in Woreda. Kuyyu Hospital giving services for an estimated Catchment population of 300.678 , of whom 150.098 were men and 150.580 were women. Kuyyu Hospital has a TB 
clinic and giving DOT service by three trained nurses and Consulted General Practitioner.

The sample size was determined using a single proportion sample size calculation formula with a source of population size greater than 10.000. To determine the sample size, the study coducted at similar area Tigray, northern Ethiopia showed that $33.3 \%$ of the respondents did not know the cause of $\mathrm{TB}^{[9]}$ and, the margin of error $5 \%$ and $95 \%$ confidence interval and adding the non-responses rate of $10 \%$. Since our source population was less than 10.000 , finite population correction was performed. Accordingly, the sample size of 108 was obtained.

The data were collected using structured questionnaires which were adopted from different research conducted on a related topic. The questionnaire has four parts, which are socio-demographic, KAP. Data were collected from May 1-30, 2018 by two trained diploma nurses. Before actual data collection, the checklist was pre-tested in $5 \%$ of the patients at a near public hospitals in the Oromia region, which was not selected for the study using randomly selected patients having a follow-up in TB clinic. This helps to ensure the clarity, ordering, consistency and acceptability of the questionnaire. After this, the questionnaire was ready after necessary corrections and training was given for data collectors for three days at the time of data collection. During the data collection, the questionnaire was checked for completeness on a daily basis by the data collector themselves and the supervisors. The completed questionnaire was also rechecked by the principal investigators to maintain the quality of data.

After data collection, each questionnaire was checked for completeness, then, coded and entered into Epi-info version 3.5.1 for cleaning, editing, and analysis. The results were presented in the form of tables, figures and text using frequencies and summary statistics, such as mean, mode, standard deviation and percentage, to describe the study population in relation to relevant variables.

To confirm the ethical and legal standard of the investigator, approval was obtained from the ethical review board of Harar Health Science College. The survey was used after written consent was obtained from Kuyyu Hospital.

\section{RESULTS}

In this study, a total of 108 respondents attending in Kuyyu Hospital at TB clinic was interviewed on their KAP related to TB transmission and prevention using pre-tested questioner.

From these 108 respondents, 68 (62.9\%) were male and 40(37.1\%) were female. From a total of 108 respondents 1
$(0.9 \%)$ were $<15$ years, $5(4.6 \%)$ of them were between the age of 15-19 year, 21 (19.4\%) of them were between the age of $20-24$ years, $25(23.1 \%)$ of them were between the age of $25-29$ years, $13(12.0 \%)$ of them were between the age of 30-34 years , $12(11.1 \%)$ of them were between the age of 35-39 years, 8 (7.4\%) of them were between the age of $40-44$ years, 8 (7.4\%) of them were between the age of $45-49$ years and 15 (14.1\%) of them were $>50$ years.

In relation to respondents occupation out of 108 respondents 17 (15.7\%) were government employer, 48 (44.4\%) were private worker, 20 (18.5\%) of them were daily labor, 15 (13.9\%) of them were unemployed, 8 (7.5\%) of them were students respectively.

From a total of 108 respondents 91 (84.3\%) of them were Oromo, 15 (13.9\%) of them were Amahara and 1 (0.9\%) of them were Tigre and $1(0.9 \%)$ of them were other (i.e. Gurage).

Regarding to religion out of 108 respondents 93 (86.1\%) were orthodox, $3(2.8 \%)$ were Muslim, 11 (10.2\%) were protestant and $1(0.9 \%)$ other (i.e. wakefata) (Table 1$)$.

Concerning respondents knowledge in relation to $T B$, out of 108 respondents, 46 (42.6\%) heard about TB from health institution at health education program, 27 (25.0\%) of respondents indicated that they heard from radio, 9 (8.3\%) from TV, 5 (4.6\%) heard from radio and TV, 4 (3.7\%) heard from friends, 8 (7.4\%) heard from radio and friends, 2(1.9\%) heard from radio and health institution, $2(1.9 \%)$ heard from radio, TV, and health institution, $3(2.8 \%)$ heard from radio, $\mathrm{TV}$, health institution and friends, $2(1.8 \%)$ of the respondents showed that they heard from radio, health institution and friends (Table 2).

Table 2 shows that, from the total of 108 respondents 46 (42.6\%) of them know TB has vaccine, 62 (57.4\%) of them they don't know if TB has vaccine.

On the other hand, from the total of respondents 81 (75.0\%) of them know sign and symptom of TB, and only 27 (25.0\%) of them don't know sign and symptom of TB.

As the researcher understood from the collected data 81 (75.0\%) of the respondents know the sign \& symptom of TB, and $75(92.6 \%)$ of them said that cough that lasts $>2$ weeks, 29 (35.8\%) of them weight loss, 17 (21.0\%) of them fever without clear cause that lasts $>7$ days, 21 (25.9\%) of them chest pain and $9(11.1 \%)$ of them ongoing fatigue.

With regard to the question raised about ways of transmission of TB, 79 (73.1\%) of the respondents indicated that they knew the ways of transmission of TB and 29 (26.9\%) of them forwarded that they did not know the ways of trans- 


\begin{tabular}{|c|c|c|}
\hline Variables & Frequency & Percentage(\%) \\
\hline \multicolumn{3}{|l|}{ Sex of the participants } \\
\hline Male & 68 & 62.9 \\
\hline Female & 40 & 37.1 \\
\hline \multicolumn{3}{|c|}{ Age group of participants } \\
\hline$<15$ & 1 & 0.9 \\
\hline $15-19$ & 5 & 4.6 \\
\hline $20-24$ & 21 & 19.4 \\
\hline $25-29$ & 25 & 23.1 \\
\hline $30-34$ & 13 & 12.0 \\
\hline $35-39$ & 12 & 11.1 \\
\hline $40-44$ & 8 & 7.4 \\
\hline $45-49$ & 8 & 7.4 \\
\hline$\geq 50+$ & 15 & 14.1 \\
\hline \multicolumn{3}{|l|}{ Educational status } \\
\hline Illiterate & 38 & 35.2 \\
\hline Read and write & 19 & 17.6 \\
\hline 1-8 (first cycle) & 15 & 13.9 \\
\hline 9-12 (high school) & 19 & 17.6 \\
\hline Collage/University & 17 & 15.7 \\
\hline \multicolumn{3}{|l|}{ Occupation } \\
\hline Gov. employee & 17 & 15.7 \\
\hline Private & 48 & 44.4 \\
\hline Daily labourer & 20 & 18.5 \\
\hline Unemployed & 15 & 13.9 \\
\hline Students & 8 & 7.5 \\
\hline \multicolumn{3}{|l|}{ Ethnicity } \\
\hline Oromo & 91 & 84.3 \\
\hline Amhara & 15 & 13.9 \\
\hline Tigrie & 1 & 0.9 \\
\hline Other & 1 & 0.9 \\
\hline \multicolumn{3}{|l|}{ Religion } \\
\hline Orthodox & 93 & 86.1 \\
\hline Muslim & 3 & 2.8 \\
\hline Protestant & 11 & 10.2 \\
\hline Others & 1 & 0.9 \\
\hline \multicolumn{3}{|l|}{ Marital status } \\
\hline Single & 41 & 38.0 \\
\hline Married & 63 & 58.3 \\
\hline Divorced & 3 & 2.8 \\
\hline Widowed & 1 & 0.9 \\
\hline
\end{tabular}

mission of TB. Out of 79 (73.1\%) respondents who knew the ways of transmission of TB 25(31.6\%) of them stated that TB transmitted by coughing, $63(79.7 \%)$ of them said that
Table 2. Shows distribution of respondent's knowledge towards vaccination

\begin{tabular}{lcc} 
TB has vaccination & Frequency & $\%$ \\
\hline Yes & 46 & 42.6 \\
No & 62 & 57.4 \\
Total & 108 & 100.0
\end{tabular}

TB was transmitted by air droplet, 12 (15.2\%) of them said that by drinking with the same cup, $10(15.6 \%)$ of them said that by feeding together and $7(8.8 \%)$ of them said that injection of unboiled cattle milk.

As indicated by respondents, $83(76.8 \%)$ of them said that TB is curable and only $3(2.8 \%)$ of them said that TB is not curable and 22 (20.4\%) of them said they did not know TB is curable or not.

Regarding to attitude from the total of 108 respondents, 83 (76.9\%) of them agreed TB transmitted by coughing, 5 (4.6\%) disagreed and 20 (18.5\%) of the respondents were neutral (Fig. 1).

As the subjects informed to 60 (55.6\%) of them agreed that regular examination of sputum is useful for patients with $\mathrm{TB}$, and $11(10.2 \%)$ of them showed their disagreement to and only 37 (34.2\%) of the respondents did not show their agreement or disagreement (Table 3).

In line with the issue raised about whether TB has a relationship with other diseases 35 (32.4\%) agreed that TB has a relation with other diseases, 25 (23.2\%) of them showed their disagreement and only $48(44.4 \%)$ of them were neutral.

Out of 108 respondents, 65 (60.2\%) agreed overcrowding has contribution of TB transmission, 20 (18.5\%) disagreed and $23(21.3 \%)$ were neutral. From the total of 108 respondents, 60 (55.6\%) disagreed that TB can be prevented by holly water, 22 (20.3\%) agreed and 26 (24.1\%) were neutral.

Regarding the practice, from a total of 108 respondents, $58(53.7 \%)$ of them responded that they opened windows when they were in the home and $50(46.3 \%)$ of them said that they did not open windows when they were at home (Fig. 2).

As depicted in Figure 2, 55 (50.9\%) of the respondents answered that they covered their mouth during coughing to prevent TB transmission, 23 (21.3\%) of the showed that they used appropriate disposal of secretions and 30 $(27.8 \%)$ of them responded separate use of drinking and feeding objects. 


$\begin{aligned} & \text { Table 3. Show the distribution of respondent's attitude } \\
& \text { towards TB has a relationship with other diseases }\end{aligned}$
\begin{tabular}{lcc} 
TB has a relationship with other disease & Frequency & $\%$ \\
\hline Has a relationship & 35 & 32.4 \\
Has no relationship & 25 & 23.2 \\
Did nott know & 48 & 44.4 \\
Total & 108 & 100.0
\end{tabular}

On top of this, from the total of 108 respondents, 6 (5.6\%) of them used traditional methods used to control TB transmission, 59 (54.6\%) of them do not use and 43 (39.8\%) of them did not know about traditional methods used to control TB transmission. Furthermore, 54 (50\%) of them disposed sputum in prepared objects, 27 (25\%) of them disposed inside of the hole, and 27 (25\%) of them disposed in anywhere.

Concerning on treatment they take $95(88.0 \%)$ of them said that that anti TB treatment taken for 6 months, 5 (4.6\%) of them responded for 12 months and other $8(7.4 \%)$ are they don't know for how many months take the treatment. (Fig. 3).

With regard to the rapport between socio demographic characteristics and knowledge, among the 108 respondents 17 (15.7\%) of them were collage (university) graduates and about 15 (13.9\%) of them completed grade 1-8 education level.

According to the finding obtained, only 25 (23.1\%) of the respondents gained a monthly income which was greater than 1000 birr had got a chance of acquiring of TB, but 11 $(10.2 \%)$ of the respondents whose their monthly income was less than 100 birr had got chance of acquiring of TB.

Based on our results higher percentage of respondents $44.4 \%$ were private worker, which shows that chance of acquiring TB is high among them because of they do not practice ways of prevention of TB while they participate in different activities that may predispose them to TB.

\section{DISCUSSION}

According to results identified all respondents, 85 (78.8\%) of them have heard about TB from different sources, such as radio, TV, health institution and friends. However, the study conducted in Addis Ababa shows that only $98.1 \%$ of the respondents have heard about TB. This difference is may be due to attention given by individuals, personal behavior and mode of life and environmental factors.

From study finding out of 108 respondents, 46 (42.6\%) of

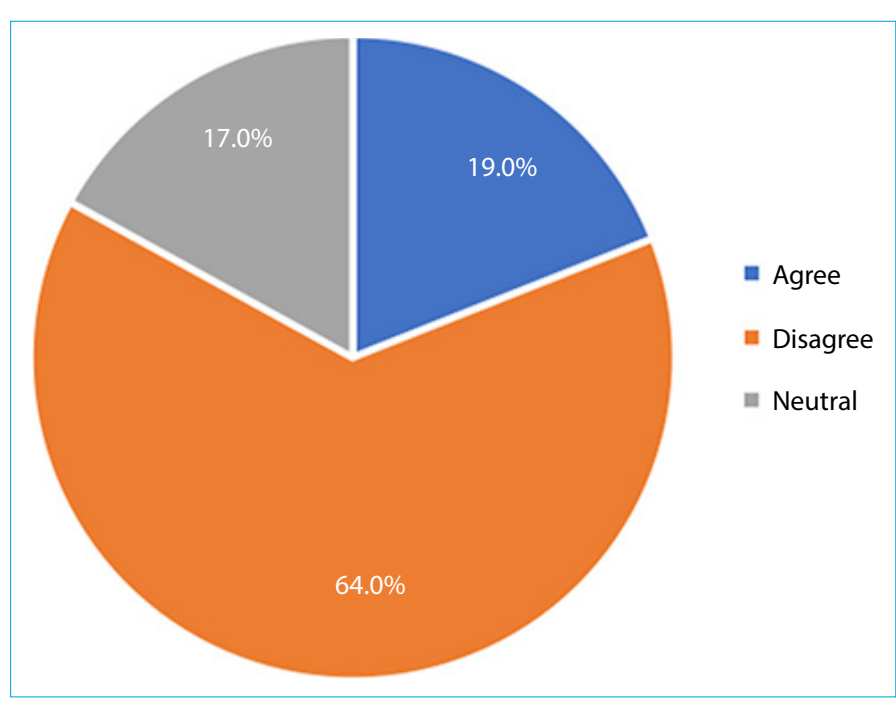

Figure 1. Shows distribution of respondents' attitude towards believes TB ordered by God as punishment.

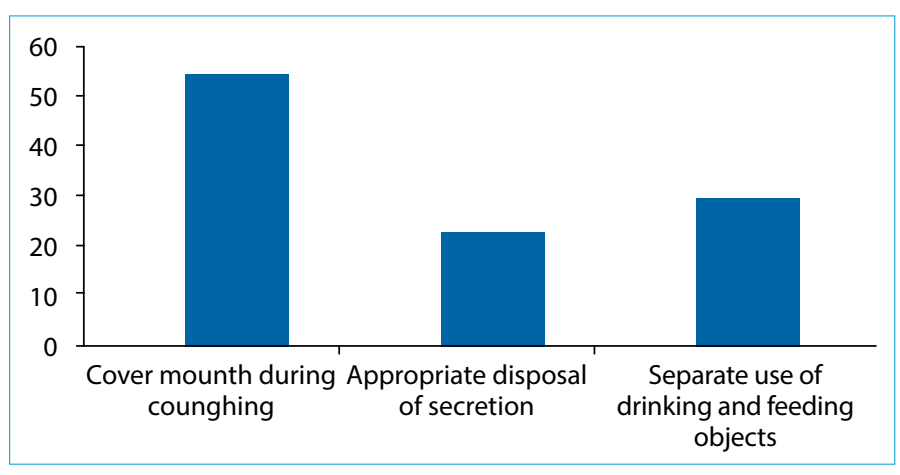

Figure 2. Respondents TB transmission and prevention behavior at Kuyyu Hospital, 2018.

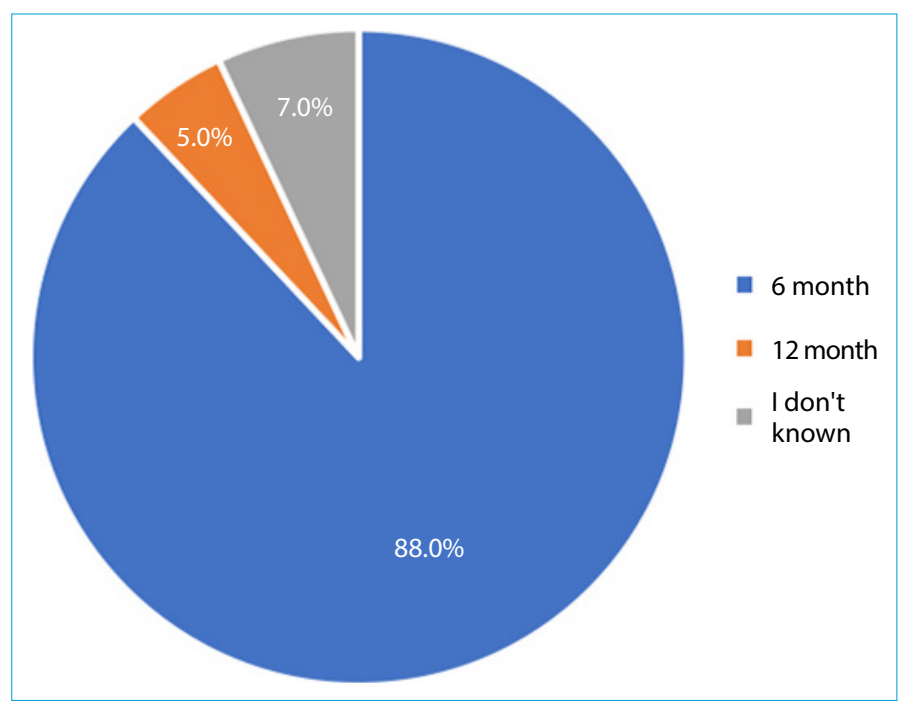

Figure 3. Treatment taken versus duration.

them know that TB has vaccination when we compare this with that of a study result at hand in Addis Ababa 53.3\% of the respondent knows as TB as vaccination. The result 
observed in Kuyyu Hospital was a little bit small, which is maybe due to the low intensity of education given and lack of using diversified teaching methodologies.

Based on the results obtained from the research conducted 81 respondents, $75 \%$ of the respondents know as the signs and symptoms of TB is cough that lasts $>2$ weeks, weight loss and fever were mentioned as signs and symptoms of TB by $69.4 \%, 26.8 \%$ and $15.7 \%$ respectively. However, a study conducted in Tigray, Northern Ethiopia shows as only $71.5 \%$ of the respondents know coughing is the signs and symptoms of TB. These differences may be due to the awareness that has been increased on TB in Kuyyu Hospital currently.

When we see the respondent's knowledge towards the mode of transmission of TB, 25 (31.6\%) respondent know as it is transmitted by coughing, the rest $79.9 \%$ by air droplet, and $15.2 \%$ by drinking with the same cup and $15.6 \%$ by feeding together. When we compare these with study results in Tigray, $62.5 \%$ TB transmitted by coughing. This difference of result may be due to community awareness about the mode of TB transmission is low in Kuyyu Hospital from that of Tigray locality. ${ }^{[9]}$

The study results indicated that 55(50.9\%) cover their mouth during coughing to prevent the transmission of TB. However, in Jimma and Hosanna's study, results show that $77.5 \%$ of the respondents practice this technique to prevent the transmission.

The difference occurred due to awareness created about the prevention techniques of TB and patients' commitment to apply the prevention techniques in their daily life.

Based on the results revealed by the researcher, 58 (53.7\%) of the respondents indicated that TB transmission was due to the habit of using ventilation of their house to prevent TB transmission, but a study conducted in Jimma and Hosanna shows that $77.5 \%$ of the respondents use ventilation to prevent the transmission of TB. ${ }^{[10]}$ This discrepancy with my result may be due to a lack of practice on what they have heard as information.

According to our results, out of 108 respondents, only 6 (5.6\%) used traditional methods used to control TB transmission. However, the study conducted in Nigeria shows that $20.6 \%$ of the respondents used traditional methods to control TB transmission. ${ }^{[1]]}$ This difference of result may be due to TB related health information given to the respondents in Kuyyu Hospital.

\section{Limitation}

The results may not be able to be generalized to all population in the town. Interviewer bias may be there especially in the questions with probing. Cause and effect relationship was also difficult to establish for the factors dealt in the study since it is cross sectional study.

\section{CONCLUSION}

$T B$ is one of the most challenging communicable diseases for developing countries, particularly in sub- Saharan Africa. According to the WHO Global TB report 2011, there where an estimated 9 million incident cases of TB globally. ${ }^{[4]}$

From a total of 108 respondents, 29 (26.9\%) did not know about the ways of TB transmission. However, the rest of 79 (73.1\%) of them know how TB is transmitted. Hence, the hospital, along with all its workers and other agencies who currently work on the prevention and controlling of TB, has to work on awareness creation about the disease transmission methods and ways of controlling it.

Concerning methods of controlling TB, six (5.6\%) used traditional methods to control it. While the rest, 59 (54.4\%) do not. Therefore, to minimize the number of patients who engage in traditional methods of TB transmission and prevention methods, education has to be given by the hospital in collaboration with other stakeholders, such as Kebele administration, other government offices and international and local NGOs.

Based on the findings and conclusions drawn the following recommendations are suggested:

In Kuyyu hospital to asses KAP of TB transmission \& prevention among TB patients the practice how to control the transmission is low. Hence, the hospital \& other concerned governmental organizations, non-governmental and community based organizations should give special attention for patients in providing necessary and basic information in relation the transmission, prevention and controlling $\mathrm{TB}$, as well Patients have to go to their nearby health institution before they get sick and to use Drugs which is ordered by physician without any interruption for possible prevention of drug resistance of TB. Moreover, patients have to get information about TB and share for his family \& his community which contributes to individual productivity as well as economic development of a country. Ministry of health also has to plan and give the job training for the staff which helps to increase their performing capacity.

\section{Disclosures}

Acknowledgment: We would like to extend appreciations to individuals who involved in data collection and Kuyyu hospital staffs who willingly gave us all the information we needed without any reservation.

Peer-review: Externally peer-reviewed. 
Conflict of Interest: None declared.

Ethics Committee Approval: The study was approved by Harar health science college Ethical board committee.

Authorship Contributions: Concept - M.L., M.T.; Design - M.L., M.T.; Supervision - M.L., M.T.; Materials - M.L., M.T.; Data collection \&/or processing - M.T.; Analysis and/or interpretation - M.L.; Literature search - M.L., M.T.; Writing - M.L.; Critical review - M.T.

\section{REFERENCES}

1. WHO. Global tuberculosis report. World Health Organization. 2016.

2. Nicas M, Nazaroff WW, Hubbard A. Toward understanding the risk of secondary airborne infection: emission of respirable pathogens. J Occup Environ Hyg 2005;2(3):143-54. [CrossRef]

3. Harries AD, Dye C. Tuberculosis. Ann Trop Med Parasitol 2006;100(5-6):415-31.

4. WHO. Country cooperation strategy at a glance. World Health Organization; 2011.

5. Getahun H. Medical and social consequences of tuberculosis in rural Ethiopia. Ethiopian Medical Journal 1999;37:174-78.

6. WHO. Global tuberculosis report. World Health Organization;
2015.

7. WHO. Global tuberculosis control: epidemiology, strategy, financing. World Health Organization; 2011.

8. WHO. Global tuberculosis control: epidemiology, strategy, financing. World Health Organization; 2009.

9. Mesfin MM, Tasew TW, Tareke IG, Mulugeta GWM, Richard M. Community knowledge, attitudes and practices on pulmonary tuberculosis and their choice of treatment supervisor in Tigray, northern Ethiopia. Ethiop J Health Dev 2005;19:21-6. [CrossRef]

10. Abebe G, Deribew A, Apers L, Woldemichael K, Shiffa J, Tesfaye $M$, et al. Knowledge, health seeking behavior and perceived stigma towards tuberculosis among tuberculosis suspects in a rural community in southwest Ethiopia. PLoS One 2010;5(10):e13339. [CrossRef]

11. Enwuru CA, Idigbe EO, Ezeobi NV, Otegbeye AF. Care-seeking behavioural patterns, awareness and diagnostic processes in patients with smear- and culture-positive pulmonary tuberculosis in Lagos, Nigeria. Trans R Soc Trop Med Hyg 2002;96(6):614-6. [CrossRef] 